\title{
Study on stress simulation of concrete floor on transversely isotropic equivalent pile foundation during construction period
}

\author{
Min Yuan ${ }^{1}$, Sheng Qiang ${ }^{1,3 *}$, Minjie $\mathrm{Hu}^{2}$, Yedong Zhang ${ }^{2}$, and Hongdan Wang ${ }^{2}$ \\ ${ }^{1}$ College of Water Conservancy and Hydropower Engineering, Hohai University, 210098 Nanjing, China \\ ${ }^{2}$ Zhejiang Water Conservancy and Hydropower Construction Holding Development Co. , 310020 Hangzhou, China \\ ${ }^{3}$ College of Civil Engineering, Xijing University, 710123 Xi'an, China
}

\begin{abstract}
In the concrete pouring process of large pumping stations, the pile foundation plays an important role in supporting the upper structures, and also has a certain constraint on the concrete floor. In the numerical simulation calculation of construction period, to simplify the pre-processing, the volume ratio method is sometimes applied to regard the pile and surrounding soil foundation as the equivalent pile foundation, while the anisotropy of pile foundation is ignored, which will result in large calculation error of the horizontal stress of the concrete floor. Aiming at this problem, the anisotropy theory of materials is adopted in this paper to simulate the temperature field and stress field of the concrete floor both on non-equivalent pile foundation and equivalent pile foundation during construction period after compiling corresponding calculation program. The results show that when the ratio $\alpha$ of the horizontal elastic modulus to the vertical elastic modulus of equivalent pile foundation is about $1 / 20$, the calculation result of the transversely isotropic equivalent pile foundation is approximately equal to the calculation result of the non-equivalent pile foundation (exact solution). It may provide some reference to similar engineering numerical simulation.
\end{abstract}

Key words. Equivalent pile foundation, Concrete floor, Thermal stress, Transversely isotropic

\section{Introduction}

As one of the obvious important characteristics of geotechnical materials, anisotropy mainly refers to the transversely isotropic (primary anisotropy) of foundation soil during the process of natural deposition and the secondary anisotropy which is presented by the different mechanical properties, parameters and structural characteristics of soil in different directions with the change of stress state under complex stress conditions. Scholars at home and abroad have done a lot of research on anisotropy theory and constitutive model of geotechnical materials. Ai et al. [1-3] obtained the foundation reaction force after solving the contact problems and parameter problems between transversely isotropic foundation and rigid strip foundation. Yang et al. $[4,5]$ established the failure criterion of transversely isotropic sand, and verified its rationality by physical tests and numerical tests. Chen et al. [6-8] deduced the solution method and calculation model of stress field of three-dimensional fracture mechanics of transversely isotropic materials based on the theory of elastic mechanics. Song et al. $[9,10]$ studied the anisotropic elastic modulus of materials.

However, the general way to simulate the stress field of large pumping station during construction period is to consider the foundation with piles as isotropic. It is different from the actual engineering because the anisotropy of the foundation material is neglected. If the foundation material is regarded as isotropic, the elastic modulus of the foundation is small, then the horizontal constraint of the concrete structures above the foudation can be well simulated but the simulation of the vertical support effect is insufficient. On the contrary, if a large value is taken for the elastic modulus of the foundation, the horizontal direction constraint will be too strong and result in excessive strict temperature control measures while the support effect of the self-weight of the concrete structures above the foundation can be well simulated. The value of the elastic modulus of the pile foundation in different directions will substancially influence the rationality and accuracy of the stress calculation results during the construction period for the concrete structures including the pile foundation, especially the pumping station floor.

The research object of this paper is a large pumping station in Zhejiang, China and the drainage pumping station is $65.2 \mathrm{~m}$ long in the water flow direction which is divided into the inlet section, the main section and the outlet section. The maximum thickness of the concrete floor is $3.5 \mathrm{~m}$, and the width of single hole is up to $11.0 \mathrm{~m}$. The overall structures of the pump station is very

* Corresponding author: sqiang2118@,hhu.edu.cn 
complicated, and the mesh of the pile foundation is greatly affected by the upper structures. Therefore, the equivalent pile foundation is used to reduce the influence of the grid on the calculation result.

Aiming at the above problems and based on the anisotropy theory, a three-dimensional finite element simulation program compiled by Fortran is used in this paper to simulate the temperature field and stress field of the concrete floor on the non-equivalent pile foundation and the equivalent pile foundation. The results were compared and analyzed to try to find out the reasonable value of the horizontal elastic modulus and vertical elastic modulus of the pile foundation under transversely isotropic conditions.

\section{Elasticity flexibility matrix theory}

According to the elastic mechanics, the six stress components of the geotechnical materials under three stress states can be recorded as $\sigma_{\mathrm{x}}, \sigma_{\mathrm{y}}, \sigma_{\mathrm{z}}, \tau_{\mathrm{yz}}, \tau_{\mathrm{xz}}, \tau_{\mathrm{xy}}$, while six strain components are recorded as $\varepsilon_{\mathrm{x}}, \varepsilon_{\mathrm{y}}, \varepsilon_{\mathrm{z}}, \gamma_{\mathrm{yz}}$, $\gamma_{\mathrm{xz}}, \gamma_{\mathrm{xy}}$.

There are three mutually orthogonal elastic symmetrical planes in the orthotropic elastic body. The two sides of the same symmetrical plane have the same elastic properties in the symmetrical directions, but the elastic properties in the three directions orthogonal to each other are not the same. It is assumed that there are three elastic symmetry planes at each point of the geotechnical materials, and the direction perpendicular to the elastic symmetry plane is the elastic principal direction.

The three orthogonal elastic symmetry planes are taken as coordinate planes, and the three elastic principal directions are respectively coincident with the $\mathrm{X}, \mathrm{Y}, \mathrm{Z}$ axis. It is known from the symmetry relationship that the shear stress component can only cause shear strain while the normal stress component can only cause linear strain. The stress-strain relationship of the anisotropy is simplified by Eq. (1).

$$
\left\{\begin{array}{c}
\varepsilon_{x} \\
\varepsilon_{y} \\
\varepsilon_{z} \\
\gamma_{y z} \\
\gamma_{x z} \\
\gamma_{x y}
\end{array}\right\}=\left\{\begin{array}{cccccc}
S_{11} & S_{12} & S_{13} & 0 & 0 & 0 \\
S_{21} & S_{22} & S_{23} & 0 & 0 & 0 \\
S_{31} & S_{32} & S_{33} & 0 & 0 & 0 \\
0 & 0 & 0 & S_{44} & 0 & 0 \\
0 & 0 & 0 & 0 & S_{55} & 0 \\
0 & 0 & 0 & 0 & 0 & S_{66}
\end{array}\right\} \bullet\left\{\begin{array}{c}
\sigma_{x} \\
\sigma_{y} \\
\sigma_{z} \\
\tau_{y z} \\
\tau_{x z} \\
\tau_{x y}
\end{array}\right\}
$$

The above formula expressed by matrices is showed as the Eq. (2).

$$
\{\varepsilon\}=[C]\{\sigma\}
$$

Where [C] is called the flexibility matrix, and the stress-strain flexibility matrix can fully reflect the anisotropy of the soil.

$\mathrm{Xi}$ [11] believes that the mechanical properties parallel to the bedding plane are the same and the transversely isotropic elastomer flexibility matrix can be transformed into a more intuitive expression as shown in Eq. (3).

$$
\left\{\begin{array}{l}
\varepsilon_{x} \\
\varepsilon_{y} \\
\varepsilon_{z} \\
\gamma_{y z} \\
\gamma_{x z} \\
\gamma_{x y}
\end{array}\right\}=\left[\begin{array}{cccccc}
\frac{1}{E_{H}} & \frac{-v_{H}}{E_{H}} & \frac{-v_{V}}{E_{V}} & 0 & 0 & 0 \\
\frac{-v_{H}}{E_{H}} & \frac{1}{E_{H}} & \frac{-v_{V}}{E_{V}} & 0 & 0 & 0 \\
\frac{-v_{V}}{E_{V}} & \frac{-v_{V}}{E_{V}} & \frac{1}{E_{V}} & 0 & 0 & 0 \\
0 & 0 & 0 & \frac{2\left(1+v_{V}\right)}{E_{V}} & 0 & 0 \\
0 & 0 & 0 & 0 & \frac{2\left(1+v_{V}\right)}{E_{V}} & 0 \\
0 & 0 & 0 & 0 & 0 & \frac{2\left(1+v_{H}\right)}{E_{H}}
\end{array}\right] \cdot\left\{\begin{array}{c}
\sigma_{x} \\
\sigma_{y} \\
\sigma_{z} \\
\tau_{y z} \\
\tau_{x z} \\
\tau_{x y}
\end{array}\right\}(3)
$$

Where $E_{H}$ represents the elastic modulus in the horizontal direction $(\mathrm{MPa}), E_{V}$ represents the elastic modulus in the vertical direction $(\mathrm{MPa}), v_{H}$ represents the poisson ratio in the horizontal plane, $v_{V}$ represents the poisson ratio in the vertical plane.

\section{Numerical simulation parameters}

\subsection{Finite element model}
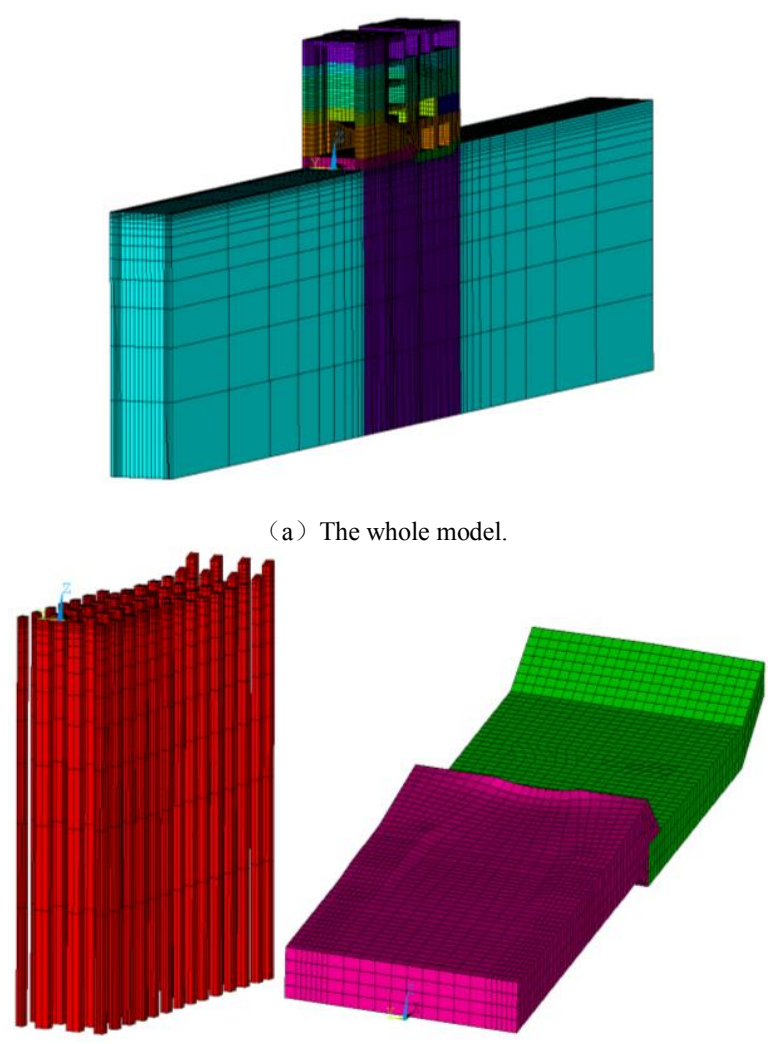

(b) Elements of the pile.

(c) Elements of the concrete floor.

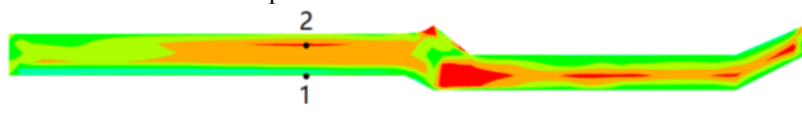

(d) The location of the feature points.

Fig. 1. Finite element model of pumping station.

The whole finite element model of the drainage pump station is shown in Fig. 1 (a). The total number of units is 86836 and the total number of nodes is 100637 . The elements of the pile are shown in Fig. 1 (b) and the elements of the concrete floor are shown in Fig. 1 (c). 
The origin of coordinates is located in the inlet channel, the $\mathrm{Z}$ axis is vertical upward, the $\mathrm{X}$ axis points to the flow direction, and the $\mathrm{Y}$ axis points to the left bank according to the right spiral rule.

In this paper, the temperature field and stress field of the whole pumping station during the construction period are simulated, but the concrete floor as the pouring layer to undertake the pile foundation and the upper structures, which is most affected by the constraint of the pile foundation. Considering the research purpose of this paper, only caculation result of the concrete floor is analyzed. The location of feature points is shown in Fig. 1(d).

\subsection{Main thermal and mechanics parameters}

The main thermal and mechanics parameters of soil, C25 concrete pile and C25 concrete floor of the pile foundation are obtained by laboratory test. The parameters of the equivalent pile foundation are shown in Table 1 after arithmetically averaging the parameters of the soil and pile based on their volume ratio.

\subsection{Temperature parameters}

For the convenience of calculation, the average monthly temperature of many years is fitted into a cosine curve [12], and the fitted formula is shown in Eq. (4). The actual values and the fitted values are shown in Table 2 .

$$
T_{a}(t)=17.1+12 \times \cos \left[\frac{\pi}{6}(t-7.2)\right]
$$

Where $T_{\mathrm{a}}$ is the air temperature $\left({ }^{\circ} \mathrm{C}\right), t$ is the time (month).

Table 1. The thermal and mechanics parameters of materials.

\begin{tabular}{cccccccccc}
\hline Category & $\begin{array}{c}\text { Thermal } \\
\text { convection } \\
(\mathrm{kJ} / \\
\left.\mathrm{m} \cdot \mathrm{h} \cdot{ }^{\circ} \mathrm{C}\right)\end{array}$ & $\begin{array}{c}\text { Specific } \\
\text { heat } \\
\left(\mathrm{kJ} / \mathrm{kg} \cdot{ }^{\circ} \mathrm{C}\right)\end{array}$ & $\begin{array}{c}\text { Thermal } \\
\text { diffusivity } \\
\left(\mathrm{m}^{2} / \mathrm{h}\right)\end{array}$ & $\begin{array}{c}\text { Adiabatic } \\
\text { temperature } \\
\text { rise } \\
\left({ }^{\circ} \mathrm{C}\right)\end{array}$ & $\begin{array}{c}\text { Linear } \\
\text { expansion } \\
\text { coefficient } \\
\left(\times 10^{-6} /{ }^{\circ} \mathrm{C}\right)\end{array}$ & $\begin{array}{c}\text { Final value of } \\
\text { autogenous } \\
\text { volume } \\
\text { deformation } \\
\left(\times 10^{-6}\right)\end{array}$ & $\begin{array}{c}\text { Density } \\
\left(\mathrm{kg} / \mathrm{m}^{3}\right)\end{array}$ & $\begin{array}{c}\text { Final } \\
\text { elasticity } \\
\text { modulus } \\
(\mathrm{MPa})\end{array}$ & $\begin{array}{c}\text { Poisson } \\
\text { ratio }\end{array}$ \\
\hline $\begin{array}{c}\mathrm{C} 25 \\
\begin{array}{c}\text { Concrete } \\
\text { Silty clay } \\
\text { Equivalent }\end{array}\end{array}$ & 6.57 & 0.93 & 0.0031 & 46.70 & 9.48 & 65.27 & 2261 & 28000 & 0.167 \\
$\begin{array}{c}\text { pile } \\
\text { foundation }\end{array}$ & 2.41 & 1.91 & 0.0012 & $/$ & 8.00 & $/$ & 1830 & 10 & 0.300 \\
\hline
\end{tabular}

Table 2. The average monthly temperature of many years in the pumping station area.

\begin{tabular}{ccccccccccc}
\hline Month & 1 & 2 & 3 & 4 & 5 & 6 & 7 & 8 & 9 & 10 \\
\hline Actual value $\left({ }^{\circ} \mathrm{C}\right)$ & 5.0 & 6.5 & 10.5 & 16.0 & 21.5 & 25.5 & 29.0 & 28.5 & 24.5 & 19.0 \\
Fitted value $\left({ }^{\circ} \mathrm{C}\right)$ & 5.2 & 6.1 & 10.0 & 15.8 & 21.9 & 26.8 & 29.0 & 28.0 & 24.1 & 18.3 \\
\hline
\end{tabular}

\section{Analysis of calculation results}

\subsection{Simulation cases}

Table 3. Summary of simulation cases.

\begin{tabular}{|c|c|c|c|c|c|c|c|c|c|c|}
\hline Simulation cases & 1 & 2 & 3 & 4 & 5 & 6 & 7 & 8 & 9 & 10 \\
\hline $\begin{array}{l}\text { Pile foundation } \\
\text { simulation mode }\end{array}$ & $\begin{array}{c}\text { Accurate } \\
\text { simulation of } \\
\text { pile and soil } \\
\text { foundation }\end{array}$ & $\begin{array}{c}\text { Isotropic } \\
\text { equivalent pile } \\
\text { foundation }\end{array}$ & \multicolumn{8}{|c|}{ Transversely isotropic equivalent pile foundation } \\
\hline$E_{H}(\mathrm{MPa})$ & / & 3600 & 1800 & 900 & 600 & 400 & 300 & 180 & 90 & 30 \\
\hline$E_{V}(\mathrm{MPa})$ & / & 3600 & 3600 & 3600 & 3600 & 3600 & 3600 & 3600 & 3600 & 3600 \\
\hline$\alpha=E_{H} / E_{V}$ & I & 1 & $1 / 2$ & $1 / 4$ & $1 / 6$ & $1 / 9$ & $1 / 12$ & $1 / 20$ & $1 / 40$ & $1 / 120$ \\
\hline
\end{tabular}

\subsection{Analysis of the results of feature points}

In order to facilitate the comparative analysis of the simulation results and based on the comparison curves of the first principal stress of feature points 1 and 2 shown in Fig. 2, the simulation caculation results of the 10 cases including the accurate simulation of pile and soil foundation, the isotropic equivalent pile foundation, and the transversely isotropic equivalent pile foundation are shown in Table 4 (This paper assumes that the tensile stress is positive, and is represented by "+", while the compressive stress is negative, and is represented by "_-"). It is found that for feature point 2 , when the ratio $\alpha$ of horizontal elastic modulus to vertical elastic modulus is $1 / 20$ (case 8 ), the calculation result of transversely isotropic equivalent pile foundation is approximately equal to non-equivalent pile foundation calculation result (exact solution). The smaller the $\alpha$, the smaller the difference between the calculated results of the 
transversely isotropic equivalent pile foundation and the

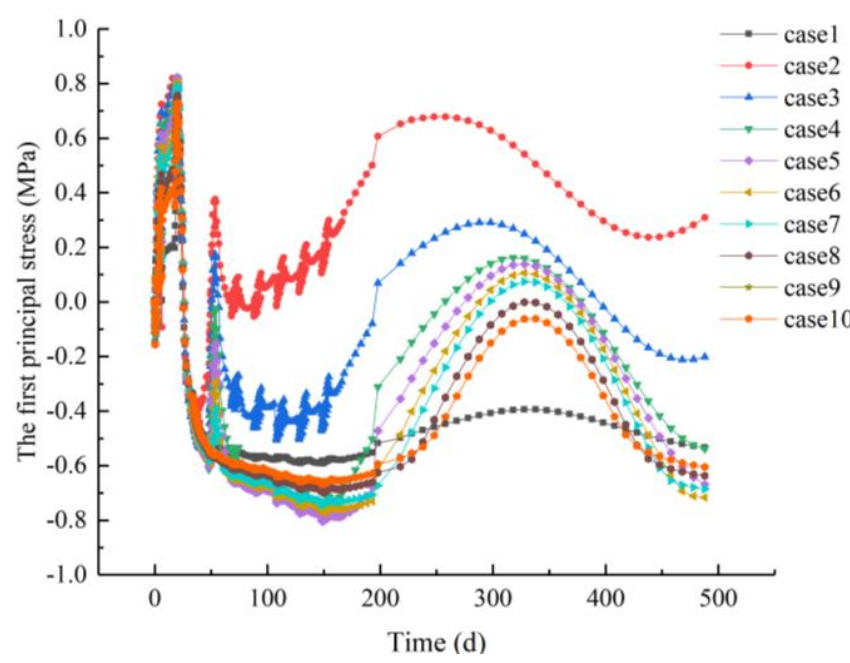

(a) Feature point 1 . non-equivalent pile foundation (exact solution).

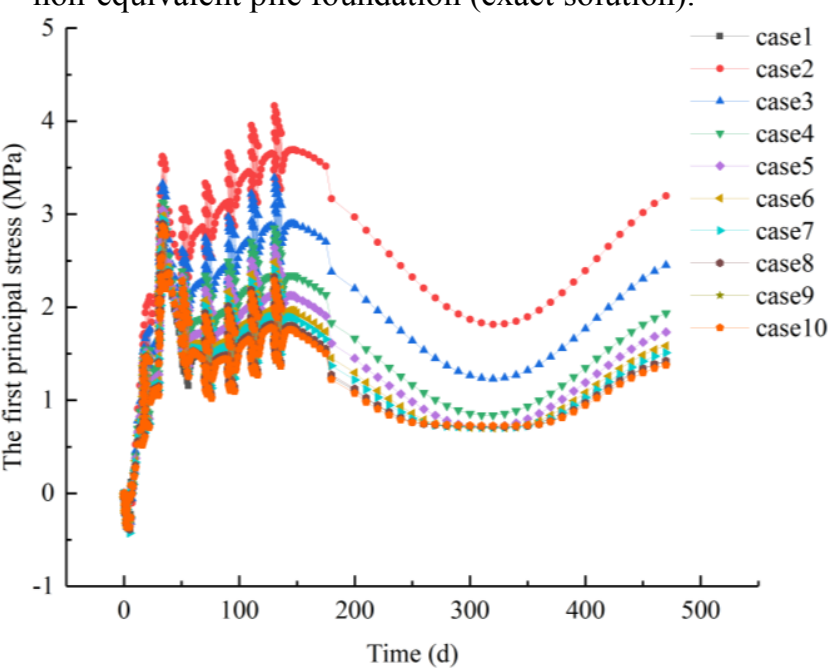

(b) Feature point 2.

Fig. 2. Comparison curve of the first principal stress of the feature points.

Table 4. Summary of simulation calculation results.

\begin{tabular}{|c|c|c|c|c|c|c|c|c|c|c|c|}
\hline \multicolumn{2}{|c|}{ Simulation cases } & 1 & 2 & 3 & 4 & 5 & 6 & 7 & 8 & 9 & 10 \\
\hline \multicolumn{2}{|c|}{$\begin{array}{l}\text { Pile foundation } \\
\text { simulation mode }\end{array}$} & $\begin{array}{l}\text { Accurate } \\
\text { simulation } \\
\text { of pile and } \\
\text { soil } \\
\text { foundation }\end{array}$ & $\begin{array}{l}\text { Isotropic } \\
\text { equivalent } \\
\text { pile } \\
\text { foundation }\end{array}$ & \multicolumn{8}{|c|}{ Transversely isotropic equivalent pile foundation } \\
\hline \multicolumn{2}{|c|}{$\alpha=E_{H} / E_{V}$} & / & 1 & $1 / 2$ & $1 / 4$ & $1 / 6$ & $1 / 9$ & $1 / 12$ & $1 / 20$ & $1 / 40$ & $1 / 120$ \\
\hline \multirow{4}{*}{$\begin{array}{l}\text { Feature } \\
\text { point } 1\end{array}$} & Maximum & +0.71 & +0.82 & +0.78 & +0.72 & +0.67 & +0.61 & +0.57 & +0.49 & +0.41 & +0.41 \\
\hline & $\begin{array}{l}\text { stress } \\
\text { (MPa) }\end{array}$ & -0.53 & +0.68 & +0.29 & +0.16 & +0.14 & +0.11 & +0.07 & -0.67 & -0.60 & -0.60 \\
\hline & $\begin{array}{l}\text { Early stage } \\
\text { Later stage }\end{array}$ & 20.5 & 16.0 & 16.0 & 16.0 & 16.0 & 16.0 & 16.0 & 16.0 & 16.0 & 16.0 \\
\hline & $\begin{array}{l}\text { Later stage } \\
\text { (d) }\end{array}$ & 328.0 & 288.0 & 288.0 & 318.0 & 318.0 & 318.0 & 318.0 & 500.0 & 500.0 & 500.0 \\
\hline \multirow{4}{*}{$\begin{array}{l}\text { Feature } \\
\text { point } 2\end{array}$} & $\begin{array}{l}\text { Maximum } \\
\text { stress }\end{array}$ & +2.85 & +4.17 & +3.39 & +3.13 & +3.05 & +2.94 & +2.92 & +2.88 & +2.87 & $\begin{array}{r}+2.87 \\
+1.28\end{array}$ \\
\hline & (MPa) & +1.41 & +3.19 & +2.45 & +1.93 & +1.73 & +1.59 & +1.51 & +1.42 & +1.38 & +1.38 \\
\hline & Early stage & 35.5 & 130.5 & 130.5 & 33.5 & 33.5 & 33.5 & 33.5 & 33.5 & 33.5 & 33.5 \\
\hline & (d) & 470.0 & 470.0 & 470.0 & 470.0 & 470.0 & 470.0 & 470.0 & 470.0 & 470.0 & 470.0 \\
\hline
\end{tabular}

From the caculation results, the difference of tensile stress between non-equivalent pile foundation and equivalent pile foundation is small at the early stage and the main reason is that the elastic modulus of concrete is not very large in the early growth process compared to its modulus at mature period. For the later stage of the first principal stress duration curve of feature point 1 , the caculation results of the non-equivalent pile foundation (exact solution) are quite different from those of the equivalent pile foundation. The former shows compressive stress while the latter shows tensile stress, and the difference is up to $1.21 \mathrm{MPa}$. The constraint effect of transversely isotropic equivalent pile foundation on the concrete floor is relatively clear in the later stage, and the force between the contact surface of the equivalent pile foundation and the concrete floor shows a tendency to increase as the ratio $\alpha$ increases. The main reason is that the concrete has a relatively large elastic modulus when the concrete is basically mature.

In the later stage of concrete age, due to the combination of shrinkage deformation of temperature drop and external restraint, mass concrete structures are prone to appear the type of the "from inside to surface" cracks. The crack initiation points in the later stage are usually inside the concrete, and it will become penetrating crack. The greater the shrinkage deformation of the later temperature drop and external constraint are, the greater the tensile stress will be. For the contact surface of the equivalent pile foundation and the concrete floor, the greater the ratio $\alpha$, the greater the maximum tensile stress in the contact surface between the equivalent pile foundation and concrete floor. 


\section{Conclusions}

(1) In the case where the transverse isotropic equivalent vertical elastic modulus is the same, the stress in the contact surface between the equivalent pile foundation and the concrete floor shows a tendency to increase as the ratio $\alpha$ of the horizontal elastic modulus to the vertical elastic modulus increases.

(2) The maximum tensile stress on the contact surface between the equivalent pile foundation and the concrete floor is different from the maximum tensile stress on the contact surface between the non-equivalent pile foundation and the concrete floor, which is mainly reflected in the later stage of concrete age.

(3) When the ratio $\alpha$ of horizontal modulus of elasticity to vertical modulus of elasticity is about $1 / 20$, the calculation result of transversely isotropic equivalent pile foundation is approximately equal to that of non-equivalent foundation (exact solution). It may provide some reference to similar engineering numerical simulation.

Acknowledgements This work was financially supported by the National Natural Science Foundation of China(51679074), and the Water Conservancy Science and Technology Plan Project Foundation of Zhejiang Province.

\section{References}

1. Z. Y. Ai, Y. F. Zhang, Interactive analysis of a rigid strip footing on transversely isotropic layered soils, Chin. J. Geotech. Eng, 36, 04 (2014) 752-756.

2. Z. Y. Ai, Q. L. Wu, Analysis of a rigid rectangular plate footing on transversely isotropic subgrade. Rock. Soil. Mech, 36, 05 (2015) 1347-1351.

3. Z. Y. Ai, K. S. Yang, Parametric study on an elastic rectangle plate on transversely isotropic multi-layered soils. Chin. J. Geotech. Eng, 38, 08 (2016) 1442-1446.

4. X. Q. Yang, L. J. Zhang, Q. H. Yan, X. T. Zhang, Failure criterion for transversely isotropic sands. Chin. J. Appl. Mech, 30, 03 (2013) 304-310+469-470.

5. W. Cao, R. Wang, J. M. Zhang, New strength criterion for sand with cross-anisotropy. Chin. J. Geotech. Eng, 38, 11 (2016) 2026-2032.

6. M. C. Chen, A. G. Zhang, Three-dimensional fracture mechanics for transversely isotropic materials. Chin. J. Theoret. Appl. Mech, 05 (2006) 612-617.

7. M. C. Chen, Three-dimensional numerical analysis of cracks in transversely isotropic materials. Chin. J. Comput. Mech, 26, 01 (2009) 109-113+119.

8. X. G. Li, L. P. Yi, Z. Z. Yang, A pseudo three-dimensional stress model of horizontal borewell in transversely isotropic formation. Chin. J. Rock. Mech. Eng, 36, 06 (2017) 1452-1459.
9. Y. J. Song, H. S. Hu, Variation of effective elastic mo duli of a solid with transverse isotropy due to aligned inhomogeneities. Acta. Phys. Sin-Ch. Ed, 63, 01 (2014) 282-294.

10. H. Bao, F. Q. Wu, P. C. Xi, Analysis of characteristics and influencing factors of elastic modulus of jointed rock mass based on statistical constitutive relation. Rock. Soil. Mech, 37, 09 (2016) 2505-2512+2520.

11. D. Y. Xi, L. Chen, T. Zhang, Anisotropic deformation of sandstone. Chin. J. Rock. Mech. Eng, 01(1995) 49-58.

12. B. F. Zhu, Thermal Stresses and Temperature Control of Mass Concrete, China Electric Power Press, Beijing, 1999. 